\title{
Importance of Thiol/Disulfide Homeostasis and the Neutrophil-to- Lymphocyte Ratio in Diagnosing of Urinary Tract Infections in the Emergency Department
}

\author{
Șervan Gökhan' (1) , Fatih Tanrıverdi' (1) , Gül Pamukçu Günaydın² (1), Çağdaș Yıldırım (1), Fatih Ahmet Kahraman² (1), \\ Ayhan Özhasenekler' (1), Gülhan Kurtoğlu Çelik' (1), Özcan Erel ${ }^{3}$ (i)
}

'Department of Emergency Medicine, Ankara Yıldırım Beyazıt University School of Medicine, Ankara, Turkey

${ }^{2}$ Department of Emergency Medicine, Ankara Atatürk Training and Research Hospital, Ankara, Turkey

${ }^{3}$ Department of Biochemistry, Ankara Yıldırım Beyazıt University School of Medicine, Ankara, Turkey

ORCID IDs of the authors: S.G. 0000-0002-I758-3383; F.T. 0000-000I-9959-5769; G.P.G. 0000-000I-853I-459I; C..Y. 0000-000I-7456-5395; F.A.K. 0000-000I-8002-0404; A.Ö. 0000-0002-2707-4099; G.K.C.. 0000-0003-I259-3694; Ö.E. 0000-0002-2996-3236.

Cite this article as: Gökhan Ș, Tanrıverdi F, Pamukçu Günaydın G, Yıldırım Ç, Kahraman FA, Özhasenekler A, et al. Importance of Thiol/ Disulfide Homeostasis and the Neutrophil-to-Lymphocyte Ratio in Diagnosing of Urinary Tract Infections in the Emergency Department. Cyprus J Med Sci 2019; 4(1): 19-23.

\section{BACKGROUND/AIMS}

The aim of this study was to investigate the diagnostic utility of thiol/disulfide homeostasis parameters, which are oxidative stress markers, together with the neutrophil-to-lymphocyte ratio (NLR) in diagnosing of urinary tract infections (UTI) in the emergency department (ED).

\section{MATERIAL and METHODS}

The study was conducted prospectively and included 63 patients who were admitted to the ED between May I5th, 2018, and October Ist, 2018 , and 59 healthy subjects included as the control group. A new method developed by Erel and Neșelioğlu was used to measure the thiol/disulfide homeostasis parameters (thiol, disulfide, disulfide/native thiol, disulfide/total thiol, native thiol/total thiol), and the NLR was studied in the patient and control groups. In addition, the relationship between these parameters and the body temperature and urinary cultures in patients with UTI was investigated as well.

\section{RESULTS}

The NLR, disulfide/native thiol, and disulfide/total thiol mean values were found to be significantly higher $(p<0.001,0.013$ and 0.009 , respectively) in patients with a UTI compared to the control group. Disulfide, disulfide/native thiol, and disulfide/total thiol mean values were found to be significantly higher $(p<0.001,<0.001$ and $<0.001$ respectively) in the group with a high body temperature compared to the group without high temperature. Native thiol and total thiol values were found to be significantly lower $(p=0.048$ and 0.020 , respectively) in the group with a positive urine culture compared to the group with a negative urine culture.

\section{CONCLUSION}

Thiol/disulfide homeostasis parameters together with the NLR values are diagnostically useful in patients with UTI.

Keywords: Thiol/disulfide homeostasis, urinary tract infection, neutrophil-to-lymphocyte ratio

\section{INTRODUCTION}

Urinary tract infection (UTI) is a clinical condition that affects approximately 150 million people annually across the world (I). UTI may occur in a wide range of clinical manifestations, from asymptomatic bacteriuria to urosepsis. Nevertheless, it may be seen frequently at any age (newborns to elderly). UTI can be caused by microorganisms such as bacteria, fungi, protozoa, and viruses, and bacterial infections often originate from the enteric flora. The most commonly detected bacteria is Escherichia Coli (2-4).

To diagnose UTI, an anamnesis, medical examination, laboratory examinations, and if needed radiological examinations, are used. Burning and pain while urinating, the feeling of compression in the suprapubic area, and an increase in the urinary frequency are seen frequently in patient's history. The leukocyte count in a complete blood count, C-reac- 
tive protein, and the erythrocyte sedimentation rate are used as blood laboratory examinations. Measuring 5-10 leukocytes in each microscopic field of a centrifuged urine sample or positive leukocyte esterase are commonly used in urinary laboratory examinations. In addition, the urine culture is also used in diagnosis (5-7).

Tissue damage may develop in UTI, and inflammatory mediators are released. Acute phase reactants, cytokines, and oxidation products are the mediators that reveal this damage. Especially reactive oxygen products that emerge due to oxidative stress in bacterial infections play a key role in the cell and tissue damage $(8,9)$. The release of cytokines and proteolytic enzymes in addition to the level of leukocyte infiltration and inflammation are important factors in the scar formation and renal fibrosis $(I 0, I)$. Many biochemical parameters that show a systemic inflammatory response in UTI have been studied, but none of them is safe and correct enough for making diagnosis $(12,13)$.

The neutrophil-to-lymphocyte ratio (NLR) is a strong predictor of an inflammatory response; it is inexpensive and can easily be obtained. The NLR has been studied in many clinical scenarios, from infections to chronic diseases, and it is used as an indicator of systemic inflammation and infection (14-16).

Mediators that are released as a result of oxidative stress cause many systemic diseases and this diseases courses with inflammation. Thiol/disulfide homeostasis parameters are used in the detection of oxidative stress, and it has been measured since 1979 single directionally. Today, these parameters can be measured both separately and also collectively by a new method that was developed by Erel and Neșelioğlu (17-19).

To the best of our knowledge, no study that investigated thiol/ disulfide homeostasis parameters and the relation between the NLR and UTI has been published by now. The aim of this study was to investigate the diagnostic utility of thiol/disulfide homeostasis parameters together with the NLR in diagnosing of UTI in emergency department (ED) patients.

\section{MATERIAL and METHODS}

Approval for this study was received from the Ankara Yıldırım Beyazit University Ethics Committee according to the latest version of the Helsinki Declaration. The study was conducted between May 15th, 2018 and October Ist, 2018, in an urban ED with approximately 150,000 patient visits per year. Sixty-three patients who were diagnosed with a UTI and were followed up and discharged from the ED were included in the study prospectively. Fifty-nine healthy subjects who shared similar characteristics with the patient group regarding age and gender were identified as the control group. Informed consent was obtained from both the patients and healthy subjects. In addition, the patient group was divided into two subgroups according to the body temperature (high/not high), and the results of urine culture (positive/negative). Thiol/disulfide homeostasis parameters and NLR values were compared between the groups.

Age, gender, presenting complaint, medical background, accompanying systemic diseases, symptoms, and findings at the time of presenting to the emergency department (dysuria, thamuria, urinary urgency, abdominal and/or flank pain, high temperature $\left[\geq 38.3^{\circ} \mathrm{C}\right]$ ), physical examination findings, laboratory results, and imaging results of the patients were registered on the standard study forms. Patients $\leq 18$ years of age, pregnant patients, patients with chronic and inflammatory diseases, patients who used drugs or had substance-use disorders, who used antibiotics, and who had an infectious disease episode in the past month were excluded from the study. Patients who were hospitalized were also excluded.

Blood samples were drawn from each patient to study a complete blood count, liver and renal function tests, electrolytes, and thiol/disulfide homeostasis parameters (thiol, disulfide, native thiol, disulfide/native thiol, disulfide/total thiol, native thiol/total thiol) levels. Urine samples were obtained to examine the urine microscopy and cultures.

Native thiol and total thiol values were measured using a new method developed by Erel and Neșelioğlu (17), and disulfide, disulfide/native thiol, disulfide/total thiol, and native thiol/total thiol values were calculated. The NLR ratio was calculated by proportioning the neutrophil and lymphocyte values.

\section{Statistical Analysis}

Results were presented as the mean+standard deviation. The normality analysis was made using the Kolmogorov-Smirnov test. A p-value $>0.05$ was accepted as normally distributed data. Univariate statistical analyses were made using the chisquare test for categorical valuables and Student's t test for continuous variables. A p-value $<0.05$ was accepted as statistically significant.

\section{RESULTS}

Thirty-four out of 63 patients who were included in the study were male. The mean age of the patient group was $40.86 \pm 18.36$ years. There were 33 male and 26 female subjects in the control group, and the mean age was $36.03 \pm 8.93$ years. There was no statistically significant difference between the patient group and the control group regarding age and gender $(p=0.066$ and 0.266 , respectively).

When the patient and control groups were compared according to the NLR and thiol/disulfide homeostasis parameters, NLR, disulfide/native thiol and disulfide/total thiol, the average values were found to be significantly higher (respectively, $p<0.001,0.013$ and 0.009 ) and the native thiol and total thiol average values were found to be significantly lower (respectively, $p=0.004$ and 0.001 ) in the patient group compared to the control group. NLR and thiol/disulfide homeostasis parameters of the patient and control groups are presented in Table I. When the high body temperature group was compared to the group without a high body temperature, the NLR and thiol/disulfide homeostasis parameters; disulfide, disulfide/native thiol, and disulfide/total thiol average valves were found to be significantly high (respectively, $p<0.001$, 0.001 , and 0.001 ), and native thiol/total thiol average values were found to be significantly low (respectively $p=0.017$ and $<0.00$ l) in the group with a high temperature. A comparison 
of thiol/disulfide homeostasis parameters and NLR values according to body temperature in the patient group is presented in Table 2. When the patient group was divided into a culture negative and positive, and the NLR and thiol/disulfide homeostasis parameters were compared, native thiol and total thiol values were found to be significantly lower (respectively, $p=0.048$ and $=0.020$ ) in the group with microbial growth in culture compared to the group without the growth. The comparison of thiol/disulfide homeostasis parameters and NLR values according to microbial growth in culture in the patient group is presented in Table 3.

TABLE I. Comparison of thiol/disulfide homeostasis and NLR levels of the patient group and the control group

\begin{tabular}{|lccc|} 
& $\begin{array}{c}\text { Patient Group } \\
(\mathbf{n}=63)\end{array}$ & $\begin{array}{c}\text { Control Group } \\
(\mathbf{n}=59)\end{array}$ & $\mathbf{p}$ \\
\hline Native thiol $(\mu \mathrm{mol} / \mathrm{L})$ & $405.25 \pm 106.00$ & $450.14 \pm 54.32$ & 0.004 \\
Total thiol $(\mu \mathrm{mol} / \mathrm{L})$ & $447.06 \pm 106.72$ & $499.53 \pm 53.97$ & 0.001 \\
Disulfide $(\mu \mathrm{mol} / \mathrm{L})$ & $25.48 \pm 12.40$ & $22.92 \pm 11.06$ & 0.231 \\
Disulfide/native thiol & $0.068 \pm 0.044$ & $0.052 \pm 0.027$ & 0.013 \\
Disulfide/total thiol & $0.059 \pm 0.032$ & $0.045 \pm 0.023$ & 0.009 \\
Native thiol/total thiol & $0.903 \pm 0.069$ & $0.901 \pm 0.052$ & 0.867 \\
NLR & $5.42 \pm 2.31$ & $1.47 \pm 0.67$ & $<0.001$ \\
\hline NLR: neutrophil-to-lymphocyte ratio & & \\
\hline
\end{tabular}

TABLE 2. Comparison of thiol/disulfide homeostasis parameters and NLR values in the patient group with high body temperatures and without high body temperatures

\begin{tabular}{|lccc|} 
& $\begin{array}{c}\text { With High } \\
\text { Temperature } \\
(\boldsymbol{n}=33)\end{array}$ & $\begin{array}{c}\text { Without High } \\
\text { Temperature } \\
(\mathbf{n}=30)\end{array}$ & $\mathbf{p}$ \\
\hline Native thiol $(\mu \mathrm{mol} / \mathrm{L})$ & $379.09 \pm 104.97$ & $442.49 \pm 97.69$ & 0.017 \\
Total thiol $(\mu \mathrm{mol} / \mathrm{L})$ & $428.73 \pm 107.50$ & $473.14 \pm 102.00$ & 0.102 \\
Disulfide $(\mu \mathrm{mol} / \mathrm{L})$ & $32.01 \pm 11.24$ & $16.19 \pm 6.81$ & $<0.001$ \\
Disulfide/native thiol & $0.090 \pm 0.045$ & $0.037 \pm 0.014$ & $<0.001$ \\
Disulfide/total thiol & $0.076 \pm 0.029$ & $0.034 \pm 0.014$ & $<0.001$ \\
Native thiol/total thiol & $0.879 \pm 0.080$ & $0.936 \pm 0.024$ & $<0.001$ \\
NLR & $5.41 \pm 1.66$ & $5.43 \pm 3.04$ & 0.971 \\
\hline NLR: neutrophil-to-lymphocyte ratio & & \\
\hline
\end{tabular}

TABLE 3. Comparison of thiol/disulfide homeostasis parameters and NLR values in the patient group with microbial growth and without microbial growth

\begin{tabular}{|lccc|} 
& $\begin{array}{c}\text { With Microbial } \\
\text { Growth }(\mathbf{n}=19)\end{array}$ & $\begin{array}{c}\text { Without Microbial } \\
\text { Growth }(\mathbf{n}=\mathbf{4 4})\end{array}$ & $\mathbf{p}$ \\
\hline Native thiol $(\mu \mathrm{mol} / \mathrm{L})$ & $363.40 \pm 108.19$ & $423.33 \pm 100.96$ & 0.048 \\
Total thiol $(\mu \mathrm{mol} / \mathrm{L})$ & $400.23 \pm 98.99$ & $467.28 \pm 104.56$ & 0.020 \\
Disulfide $(\mu \mathrm{mol} / \mathrm{L})$ & $25.42 \pm 11.20$ & $25.51 \pm 13.01$ & 0.978 \\
Disulfide/native thiol & $0.082 \pm 0.059$ & $0.063 \pm 0.035$ & 0.191 \\
Disulfide/total thiol & $0.069 \pm 0.041$ & $0.054 \pm 0.026$ & 0.163 \\
Native thiol/total thiol & $0.895 \pm 0.089$ & $0.906 \pm 0.059$ & 0.610 \\
NLR & $5.80 \pm 1.33$ & $5.25 \pm 2.62$ & 0.277 \\
\hline NLR: neutrophil-to-lymphocyte ratio & & \\
\hline
\end{tabular}

\section{DISCUSSION}

There is an increase in the production of pro-inflammatory cytokines associated with increased oxidative stress mediators in many diseases where inflammation is in the forefront. Thiol/ disulfide homeostasis is also one of the oxidative stress markers (19). Thiol/disulfide homeostasis plays a significant role in detoxification, signal transduction, apoptosis, and the regulation of enzyme activities. Disturbance in the thiol/disulfide balance plays a part in the development process of many inflammatory diseases such as diabetes mellitus, cardiovascular diseases, rheumatoid arthritis, chronic renal failure, cancer, and Alzheimer's and Parkinson's (20-22). The NLR is a systemic inflammation parameter that is being investigated to be used in the diagnosis of inflammatory and infectious conditions. It is an indicator with a predictive value in the conditions that cause inflammation, especially bacterial infections $(23,24)$.

Changes in thiol/disulfide homeostasis have been investigated in some studies, especially with regard to infections, in the literature $(25,26)$. We found that the NLR was also investigated in the infection setting in medical literature $(24,27)$. A correlation between the NLR and UTI was detected in a study by Han et al. (28). Similar results were found in the study by Lee et al. (29). In our study, NLR values were significantly higher in the group with UTI compared to the control group, consistent with the literature.

In our literature review, we could not find any studies investigating the relationship between thiol/disulfide homeostasis and a UTI infection. Our study was, to the best of our knowledge, the first one that investigated this relationship in the literature. Disulfide/native thiol and disulfide/total thiol average values were found to be significantly higher in the patient group with UTI compared with the control group; contrary to this, native thiol and total thiol average values were found to be significantly lower. This result is in line with the studies in the literature showing the increase of thiol/disulfide homeostasis parameters in cases of infection and inflammation (30).

Disulfide, disulfide/native thiol, and disulfide/total thiol average values were detected as significantly high in the group with high temperature compared to the group without temperature. As for native thiol and native thiol/total thiol average values, they were detected as significantly low. No significant difference was observed between the two groups regarding the NLR. This result was deemed compatible with the low thiol-to-disulfide ratio, as shown in the studies that were made in conditions with inflammation $(25,31)$.

A direct correlation between the NLR and bacterial infections was shown by some studies $(32,33)$. Sarier et al. $(34)$ stated that they found the culture positivity at approximately $30 \%$ in their study in patients with urethral stent, and they detected a significant correlation between increasing the duration of stent and a high NLR. The culture positivity was found similarly at approximately $30 \%$ in our study too, but no significant correlation between the NLR and culture positivity was detected. Regarding thiol/disulfide parameters, only low native and total thiol values were found to be significant in the group with microbial growth in culture. We think that the inflammation degrees may be higher 
in bacterial infections $(35,36)$, but in our study, a low number of patients with microbial growth in culture might be the reason for our results.

We think that studying thiol/disulfide homeostasis parameters together with the NLR may be diagnostically useful in UTI diagnosing, and more large-scale studies with a higher number of cases are needed in this respect. In our study, the gender distribution is not compatible with the literature, and this can be explained by the low number of our patient population.

We could not find any studies investigating UTI and NLR and thiol/disulfide homeostasis together in the literature. To the best of our knowledge, our study is the first one in this respect.

Ethics Committee Approval: Ethics committee approval was received for this study from the Ethics Committee of Ankara Yıldırım Beyazıt University School of Medicine (Approval Date: 07.05.2018, Approval Number: 104).

Informed Consent: Informed consent was obtained from the patient who participated in this study.

Peer-review: Externally peer-reviewed

Author contributions: Concept - Ș.G., F.T.; Design - Ș.G., A.Ö., Ö.E.; Supervision - Ș.G., A.Ö., Ö.E.; Resource - Ș.G., F.T., C.Y., G.P.G., G.K.C., F.A.K.; Materials - S..G., F.T., C.Y., G.P.G., G.K.C.., F.A.K.; Data Collection and/or Processing - S.G., F.T., C.Y., G.P.G., G.K.C.., F.A.K.; Analysis and/or Interpretation - Ș.G., A.Ö., Ö.E.; Literature Search - Ș.G., F.T., C.Y., G.P.G., G.K.C., F.A.K.; Writing - Ș.G., F.T., C.Y., G.P.G., G.K.C.., F.A.K., A.Ö., Ö.E.; Critical Reviews S.G., A.Ö., Ö.E.

Conflict of Interest: The authors have no conflicts of interest to declare.

Financial Disclosure: The authors declared that this study has received no financial support.

\section{REFERENCES}

I. Stamm WE, Norrby SR. Urinary tract infections: disease panorama and challenges. J Infect Dis 200I; 183(suppl I): I-4. [CrossRef]

2. Sobel JD, Kaye D. Urinary tract infection. In: Mandell GL, Bennett JE, Dolin R(eds). Principles and Practice of Infectious Diseases. 4th ed. New York: Churchill Livingstone, 1995: 662-90

3. Gupta K, Stamm WE. Pathogenesis and managment of recurrent urinary tract infections in women. World J Urol 1999; 17: 415-20. [CrossRef]

4. Nielubowicz GR, Mobley HL. Host-pathogen interactions in urinary tract infection. Nat Rev Urol 20I0; 7: 430-4I. [CrossRef]

5. Öztürk U, İmamoğlu MA. Antibiotic Applications in Uncomplicated Urinary Tract Infections. Turk Urol Sem 20I0; I: 226-3I. [CrossRef]

6. Rubin R, Shapiro ED, Andriole VT, Davis RJ, Stamm WE. General guidelines for the evaluation of new anti-infective drugs for treatment of urinary tract infection. Clin Infect Dis 1992; 15(suppl): 216-27. [CrossRef]

7. Stamm WE, Hooton TM. Managment of urinary tract infections in adults. N Engl J Med 1993; 329: 1328-34. [CrossRef]

8. Smith EA. Pyelonephritis, renal scarring and reflux nephropathy : a pediatric urologist's perspective. Pediatr Radiol 2008; 38(suppl I): S76-82. [CrossRef]

9. Grover S, Srivastava A, Lee R, Tewari AK, Te AE. Role of inflammation in bladder function and interstitial cystitis. Ther Adv Urol 20Il; 3: 19-33. [CrossRef]

10. Shihamura T. Mechanisms of renal tissue destruction in an experimental acute pyelonephritis. Exp Mol Pathol 1981; 34: 34-42. [CrossRef]

II. Monga M, Roberts JA. The possible role of granulocyte elastase in renal damage from acute pyelonephritis. Pediatr Nephrol 1995; 9: 583-6. [CrossRef]
12. Tekin M, Konca C, Gulyuz A, Uckardes F, Turgut M. Is the mean platelet volume a predictive marker for the diagnosis of acute pyelonephritis in children? Clin Exp Nephrol 2015; 19: 688-93. [CrossRef]

13. Shaikh N, Borrell JL, Evron J, Leeflang MM. Procalcitonin, C-reactive protein and erythrocyte sedimantation rate fort he diagnosis of acute pyelonephritis in children. Cochrane Database Syst Rev 2015; I: CD009185. [CrossRef]

14. Bhat T, Teli S, Rijal J, Bhat H, Raza M, Khoveiry G et al. Neutrophil to lymphocyte ratio and cardiovascular diseases:a review. Expert Rev Cardiovasc Ther 2013; II: 55-9. [CrossRef]

15. Lowsby R, Gomes C, Jarman I, Lisboa P, Nee PA, Vardhan M et al. Neutrophil to lymphocyte count ratio as an early indicator of blood stream infection in the emergency department. Emerg Med J 2015; 32: 53I-4. [CrossRef]

16. Bolat D, Topcu YF, Aydogdu O, Minareci S, Dincel C. Neutrophil to lymphocyte ratio as a predictor of early penile prosthesis implant infection. Int Urol Nephrol 2017; 49: 947-53. [CrossRef]

17. Erel O, Neselioglu S. A novel and automated assay for thiol/disulphide homeostasis. Clin Biochem 20l4; 47: 326-32. [CrossRef]

18. Ellman G, Lysko H. A precise method for the determination of whole blood and plasma sulfhydryl groups. Anal Biochem 1979; 93: 98-102. [CrossRef]

19. Horton JW. Free radicals and lipid peroxidation mediated injury in burn trauma: The role of antioxidant therapy. Toxicology 2003; 189: 75-88. [CrossRef]

20. Biswas S, Chida AS, Rahman I. Redox modifications of proteinthiols:emerging roles in cell signaling. Biochem Pharmacol 2006; 71: 55I-64. [CrossRef]

21. Kundi H, Erel Ö, Balun A, Çiçekçiog lu H, Cetin M, Kiziltunç E, et al Association of thiol/disulfide ratio with syntax score in patients with NSTEMI. Scand Cardiovasc J 2015; 49: 95-100. [CrossRef]

22. Eren Y, Dirik E, Neselioglu S, Erel O. Oxidative stress and decreased thiol level in patients with migraine: cross-sectional study. Acta Neurol Belg 2015; II5: 643-9. [CrossRef]

23. Holub M, Beran O, Kasprikova N, Chalupa P. Neutrophil to lymphocyte count ratio as a biomarker of bacterial infections. Open Med 2012; 7: 258-61. [CrossRef]

24. Liu $X$, Shen $Y$, Wang $H, G e$, Fei A, Pan S. Prognostic significance of neutrophil to lymphocyte ratio in patients with sepsis: a prospective observational study. Mediators Inflamm 2016; 2016: 8191254. [CrossRef]

25. Kara SS, Erel O, Demirdağ TB, Cura Yayla BC, Gulhan B, Neselioglu $\mathrm{S}$, et al. Alteration of thiol-disulphide homeostasis in acute tonsillopharyngitis. Redox Rep 2017; 22: 205-9. [CrossRef]

26. Kolgelier $S$, Ergin $M$, Demir LS, Inkaya AC, Aktug Demir N, Alisik M, et al. Impaired Thiol-Disulfide Balance in Acute Brucellosis. Jpn J Infect Dis 2017; 70: 258-62. [CrossRef]

27. Nam KW, Kim TJ, Lee SJ, Kwon HM, Lee YS, Ko SB, et al. High neutrophil to lymphocyte ratio predicts stroke-associated pneumonia. Stroke 2018; 49: 1886-92. [CrossRef]

28. Han SR, Lee IR, Park SJ, Kim JH, Shin JI. Usefulness of neutrophil lymphocyte ratio in young children with febrile urinary tract infection. Korean J Pediatr 2016; 59: 139-44. [CrossRef]

29. Lee JW, Park SJ, Park KB, Yoo GH, Kim SS, Lee SM. Prediction of renal cortical defect and scar using neutrophil to lymphocyte ratio in children with febril urinary tract infection. Nuklearmedizin 2017; 56: 109-14. [CrossRef]

30. Parlak ES, Alisik M, Hezer H, Karalezli A, Hasanoglu HC, Erel O. Evalvation of dynamic thiol/disulphide redox state in community-acquired pneumonia. Saudi Med J 2018; 39: 495-9. [CrossRef]

31. Kundi H, Gök M, Çetin M. Association of thiol disulfide homeostasis with slow coronary flow. Scand Cardiovasc J 2016; 50: 213-7. [CrossRef]

32. Wyllie DH, Bowler ICJW, Peto TEA. Relation between lymphopenia and bacteremia in UK adults with medical emergencies. J Clin Pathol 2004; 57: 950-5. [CrossRef]

33. de Jager CPC, van Wijk PTL, Mathoera RB, de Jongh-Leuvenink J, van der Poll T, Wever PC. Lymphocytopenia and neutrophil-lympho- 
cyte count ratio predict bacteremia better than conventional infection markers in an emergency care unit. Crit Care 2010; 14: RI92. [CrossRef]

34. Sarier, M., Demir, M., Duman, I., Yuksel, Y., Demirbas, A. Evaluation of ureteral stent colonization in live-donor renal transplant recipients. Transplant Proc 2017; 49: 415-9. [CrossRef]

35. Owrangi B, Masters N, Kuballa A, O'Dea C, Vollmerhausen TL, Katouli M. Invasion and translocation of uropathogenic Escherichia Coli iso- lated from urosepsis and patients with community-acquired urinary tract infection. Eur J Clin Microbiol Infect Dis 2018; 37: 833-9. [CrossRef]

36. Tufvesson E, Markstad H,Bozovic G, Ekberg M, Bjermer L. Inflammation and chronic colonization of Haemophilus Influenza in sputum in COPD patients related to the degree of emphysema and bronchiectasis in high resolution computed tomography. Int J Chron Obstruct Pulmon Dis 2017; 12: 3211-9. [CrossRef] 